Article

\title{
Women's Empowerment and Climate Change Adaptation in Gujarat, India: A Case-Study Analysis of the Local Impact of Transnational Advocacy Networks
}

\author{
Peggy Spitzer Christoff * (DD and Jamie M. Sommer \\ Department of Asian and Asian American Studies and Department of Sociology, State University of New York \\ at Stony Brook, New York, NY 11794, USA; jamie.sommer@stonybrook.edu \\ * Correspondence: peggy.christoff@stonybrook.edu \\ Received: 1 May 2018; Accepted: 4 June 2018; Published: 8 June 2018 \\ check for \\ updates
}

\begin{abstract}
As on-the-ground projects come into existence and continue to expand to adapt to climate change and empower women, it is important to understand their location within Transnational Advocacy Networks (TANs). Using Bhungroo technology, we conduct case-study research to assess the potential of TANs to increase the scope and scale of local projects as well as the ability of similar and emerging projects to create sustainable social and environmental change at local levels; (2) Using the theoretical and cross-disciplinary contributions of Keck and Sikkink and Appiah, our methodology focuses on analyzing interviews and earned media hits data from the UNFCCC Momentum for Change; (3) We find that while TANs may help increase the scale and scope of climate change projects, increasing their ability to effectively reach more people and areas is not completely certain, based on this case study; (4) We conclude by proposing ways women's political participation may be enhanced by similar projects.
\end{abstract}

Keywords: women's empowerment; climate change adaptation; India; transnational advocacy networks

\section{Introduction}

Finding sustainable solutions to climate change problems has been a perennial preoccupation of scholars and practitioners [1-3]. Throughout the world, climate change adaptation (CCA) activities have emerged on-the-ground to help resolve crises such as floods, food insecurity, and droughts linked to increases in extreme weather conditions [4,5]. Many of these local activities have gained international mass media attention for their innovation and efficiency, including recognition and support from the United Nations Framework Convention on Climate Change (UNFCCC) and partnerships with international organizations such as the International Union for Conservation of Nature and Natural Resources (IUCN). This dynamic is a key component of "transnational advocacy networks" (TANs) [6], which are networks that develop as a result of people-to-people interactions at various levels from local communities to international non-governmental organizations (INGOs).

In recent years, several local projects addressed both CCA and increasing the status of women concomitantly and were recognized by and received awards through the UNFCCC's Momentum for Change initiative with the intention of drawing attention to the success of the projects and promoting the importance of both gender and climate issues. The UNFCCC offered engagement with policy makers, public relations support, marketing support, and capacity building [5,7]. Highlights such as these tend to increase attention to the projects (in some cases, garner funding) and showcase the projects as examples for future development interventions [6]. 
Given this spotlight, scholars and practitioners are taking a closer look at these projects, especially given the pressing issues of climate change and how it interacts with gender issues [8-16]. While some projects have been evaluated in the scholarly literature (see [7]), this article focuses on one project that addresses both climate change adaptation and gender equality concomitantly, Bhungroo, which began in Gujarat, India. Through this case study, we aim to evaluate whether the TAN theories scholars propose (in particular, those highlighting the effectiveness of TANs and measures to affect social change) are apparent or operative. This case is significant to study in a TANs perspective given that it has several traceable connections and support within and outside of India. In particular, we believe it is of theoretical and practical value to learn about how the mass media facilitates the development of TANs. This will enable a greater understanding of how such programs are communicated in the public sphere as well as what aspects are muted and highlighted [6,17-20]. An evaluation of the Bhungroo project provides a backdrop (and perhaps a framework) for evaluating other projects relating to gender and CCA [21].

Our contribution, therefore, is twofold. First, in recognizing the increase of different types of media outlets and information sources in recent years, we aim to assess the potential of TANs to increase the scope and scale of local projects as well as the ability of similar and emerging projects to create sustainable social and environmental change at local levels. As climate change increases, scholars reflect upon the effectiveness of the strategies that are being used and the elements and considerations they contain (in this case, an increase in women's empowerment and participation).

Second, by evaluating the UNFCCC Momentum for Change's mass media campaign strategy vis-à-vis Bhungroo, we address the following components of social change [22]:

- Specificity (Does the mass media describe details of the Bhungroo project and/or couch it in larger, amorphous concepts?)

- Appeal (Is the language intended to gain international support and/or does it represent the cultural values and norms of women's roles?); and

- Advocacy (Do the reports also attempt to elicit public commitment and/or acknowledge significant obstacles to social change?)

In this article, we first review the scholarly literature's connections between climate change and gender issues as a fundamental part of sustainable development. Second, we introduce the Bhungroo irrigation technology developed by social entrepreneurs in Gujarat, India. Third, we define TANs and describe how Bhungroo fits within this framework. Fourth, we evaluate Bhungroo by applying Appiah's theoretical and observed measures for social change [23]. Fifth, we evaluate the effectiveness of the UNFCCC's Momentum for Change political campaign strategy. Finally, we speculate on the benefits and limitations of Bhungroo in facilitating sustainable social change.

\section{A Literature Review on Climate Change Adaptation and Women's Empowerment}

Researchers and practitioners within the sustainable development and climate change community argue that climate change and gender issues are inextricably intertwined [15,24-26]. Generally, this is thought to be the case in the developing world where women tend to be less wealthy than men, making them more vulnerable to climate change impacts $[1,8,25]$. Additionally, because of the common social positions of women as caregivers, homemakers, and food, water, and wood producers and gatherers, they are said to experience the effects of climate change more often and therefore have reason to find ways to adapt and promote sustainable solutions [24,26-32].

Though the interaction between women and climate change obviously varies by level of income, nation, region, state, and level of urbanization-among others-local and international program managers integrate gender mainstreaming into CCA interventions [22,23,31]. On the other hand, analysts question the effectiveness of this integration because inter-governmental organizations (IGOs) and INGOs often use a top-down approach and inappropriate sustainable solutions on-the-ground [33-37]. 
It appears that women-centered projects that are developed "on-the-ground" (i.e., within the geographical region of intervention) generally are viewed more favorably because they take into account local factors such as customs and laws to create sustainable solutions [7,10]. On the other hand, localized projects may be too small in scale and scope to make a difference outside of their communities [38,39].

Additionally, in many countries in the developing world, there is serious resistance to women participating in public life [32,40], though the severity varies by the strength of traditional practices and levels of democratic governance, among others $[15,33]$. Several barriers to women's political participation, including a lack of education, also may make it difficult for women to lead and participate in CCA projects [41,42].

As will be discussed below, scholars recognize that TANs are essential to funding, support, and outreach as well as to pressuring states and governments to become more gender equitable or introducing other local women to such projects [10,11]. In this study, we hope to demonstrate that on-the-ground projects can expand in scale and scope when they become connected to TANs. In the next section, we introduce our case study-the Bhungroo irrigation technology, which we chose because it addresses both climate change adaptation and gender equality simultaneously. Additionally, this case is significant to study in a TANs perspective because it has several traceable connections and support within and outside of the India.

\section{An Introduction to Bhungroo Irrigation Technology}

The Bhungroo irrigation technology, developed by Trupti Jain and Biplab Paul in Gujarat, India aims to empower poor women and improve food security, prepare for disasters, and generate income through water technology usage [41,42]. The technology is housed under an NGO, also referred to as a "social enterprise," Naireeta Services Private Limited (NSPL), and headed by Trupti and Biplab. While Naireeta Services began in 2000, the actual irrigation technology program-the focus of our case study—-took over a decade to streamline and formalize [43-45].

Trupti and Biplab developed the Bhungroo irrigation technology in response to the 2001 earthquake, which led to water scarcity that was followed by a monsoon. Over time, they improved the Bhungroo irrigation technology as a sustainable solution to steady farming in both dry and wet seasons-which both harvests and stores water for irrigation [44,45]. In simple terms, the technology helps mimic part of the natural hydrological cycle whereby water is gathered in the ground (or recharged) and then used to water crops, as well as keep the soil moist.

This entirely sustainable solution is paired with the need to improve the livelihoods of poor and semi-illiterate rural women. Naireeta Services and their partner organizations train women to use the technology and teach others, which widens their skillsets. Additionally, women are responsible for managing the technology, which helps improve their social power, especially because the majority of women do not have land rights in Gujarat. According to Trupti,

"The small farmer holds less than one hectare of land and, in our arid region, the land is in the name of the man. In India, women don't have land rights. I have tried, by working with NGOs, to give land rights in the name of the women, but we are not succeeding in that. Only the $2 \%$ of women - those who are the single child of the family-can get that. That's the official situation."

From the above information, it is clear that Naireeta Services could not help women gain land rights. Trupti discusses how Naireeta Services tried to work with NGOs to receive support to reach their goal, and that it was not enough. As a result, a very small percentage of women even had the right to own land, which made it difficult to increase women's roles and improve their lives and gender relations in the area. Despite the "official situation," Trupti describes yet another layer of social stratification in which the majority of small farmers became laborers for rich farmers. Trupti describes this as follows: 
"... Without water, they are not able to farm the land. These farmers have to purchase the water from the others, which is very costly. So, although they have the land, they are working the land as laborers of the rich farmers. So we don't have the irrigation facilities. They are working as laborers for the rich farmers."

As exemplified in the preceding statement, the dry season made it difficult for farmers to use their land. As a result, the small farmers needed something to improve their situation given the difficult weather patterns and the poor terrain resulting from issues related to climate change. According to Trupti, this is where Bhungroo came in to "take care of the land" when environmental conditions were unsuitable for farming. However, the critical addendum to the solution was improving the lives of the women in these small farming communities. While conveying the emergence of the idea to give the Bhungroo irrigation technology rights to women, Trupti discussed the fact that achieving land rights for women had yet to come to fruition despite their NGO's efforts.

Giving women the rights to the Bhungroo technology was a significant step toward giving women the control over their natural and social environments. Even though women do not have land rights, they now had rights to the tools that the farmers need to make the land useful. Thus, farmers can make their land usable if they allow women to be in charge of the technology. Working around the government's denial of giving women land rights was sustainable and actually empowered the women. They received ownership, but also learned how to use, supervise, and teach the technology. Trupti expands on this by stating that,

"... The women have to supervise the construction of the Bhungroo. We give them all other things and they contribute in the Bhungroo elections as labor workers. After the elections, the women basically are distributing the water so that they are managing the group of women farmers and the distribution of the water in that area. This is the role of the women."

Women are given the tools necessary to use, distribute, and manage the technology. Their role is therefore twofold, to help their communities adapt to difficult land and weather conditions and give them the power to decide where the water goes and when. Women can then use this power as leverage in their communities and families.

As their connections with other organizations and funders grew, so did the scale and scope of Trupti's and Biplab's creation. For instance, their Bhungroo technology and services have received several awards including the national DST Lockhead Martin India Innovation Growth Programme Innovation Award; regional recognition from Syngenta Agriculture Social Enterprise Award and the DBS-NUS Social Venture Challenge Asia Award; and international acknowledgement from UNFCCC Momentum for Change's “Women for Results" Award, the Cartier Women's Initiative Award, Buckminster Fuller Challenge, among many others. As we will discuss, it was the effective use of TANs, which have now expanded greatly, that has increased the likelihood of sustainable social change.

To accomplish their goals of adapting to the land and empowering women in Gujarat, Naireeta Services expanded the technology to other areas in India (Uttar Pradesh, Maharashtra, Karnataka, Andhra, Jharkhand and Bihar) and internationally (to Bangladesh, Ghana, Togo, Zimbabwe, and Madagascar). It has partnered with the governments of India and Togo, and several national and international organizations and with the Aquatech Cropping Produce Livelihood (ACPL), the Cartier Women's Initiative Awards, and Securing Water for Food (SWFF), among others. Naireeta Services also served as a "knowledge partner" with Sustainable Growth Initiatives (SGI), Conservation Alliance, and Lokvikas NGO.

It has received funding and support from large and growing foundations, including but not limited to:

(1) The Rockefeller Foundation (a private foundation that funds various philanthropic causes);

(2) The Deshpande Foundation (an NGO that works on large-scale projects in India and US);

(3) Government partnerships including UKAID/FICCI (a UK development partnership with India); 
(4) SWFF (an international organization promoted by USAID, the Swedish International Development Cooperation Agency (Sida), the Government of South Africa, and the Ministry of Foreign Affairs of the Kingdom of the Netherlands); and

(5) GIZ (the German Development Agency).

In sum, the women-centered Bhungroo program seems to have reduced the impact of climate change in the region and promoted a cross cutting environmentally-sustainable innovation internationally. In this next section, we define TANs and contextualize the Bhungroo project within these afore-mentioned networks.

\section{Transnational Advocacy Networks (TANs) and the Bhungroo Project}

TANs can be described as chains of advocacy, support, and/or outreach that tend to revolve around large normative global issues, such as climate change, gender equity, or both $[6,21]$. Conceptually, TANs are used to describe a process by which support is given and received through multiple intersecting channels across the world. These interactions between people and organizations are part of a global and local effort to address an array of global problems.

There are five key elements of TANs as described by social science theoreticians Keck and Sikkink. Below we describe how each of the five elements applies to the Bhungroo technology under the rubric of climate change and gender equity.

\subsection{TANs Are Organic and not Hierarchically Managed}

Our research indicates that the networks developed around Bhungroo have no obvious hierarchy. For example, Trupti, a life-long resident of Gujarat, first introduced the irrigation technology and worked within the community to develop a strategy that would both help farmers and empower women. With input from that community, she and her husband, Biplab, who had resided in Bengal, developed a local NGO, Naireeta Services Private Limited. They employed nine professionals and attracted 23 volunteers, which led to the formation of local "self-help groups" within a communal structure. Therefore, at its inception, this project did not use a "top-down" approach to improve climate change adaptation and gender equity but instead was designed to solve a local problem. As it gained momentum and expanded outside of the immediate community, this element of TANs became integral to its sustainability.

\subsection{TANs Are Initiated from outside the Country and Promoted at the Ground Level Inside the Country}

While the Bhungroo program was not initiated from outside of the country, the norms of gender and environmental adaptation were initiated outside of the country. The program does fit into larger external networks that already had been formed around climate change and gender equity. It is important to be clear here that TANs are not the program, but the larger network surrounding the program. The Bhungroo program fits within a much larger context, and therefore the fact that the program was initiated within the country, does not mean that the TANs itself was initiated inside of the country: Actually, it is just the opposite. Because of pre-existing TANs for the type of work Trupti and Biplab were doing, Trupti was named a Rockefeller Fellow and Biplab was named an Ashoka Changemaker. Receiving support from outside of the country for the program to expand was crucial to enable the organization to promote and expand on the ground. For instance, the Bhungroo program received the Buckminster Fuller Global Challenge Award in 2017 and continues to gain recognition and support for its work inside India (including Uttar Pradesh, Bihar, West Bengal, Karnataka, Gujarat, Madhya Pradesh, Rajasthan, and Haryana). This support may not have been possible if global norms surrounding gendered solutions to climate change adaptation had not existed. 


\subsection{TANs Involve Several Different Actors, and Place both International and Domestic NGOs at the Center}

Both international and domestic NGOs were crucial to the success of the Bhungroo project. Since 2014, when Naireeta Services received international recognition through the UNFCCC Momentum for Change's "Women for Results" Award, the Bhungroo project gained many new partners. The UNFCCC's 25-member advisory board, comprised of individuals from around the world, facilitated the introduction of the irrigation technology in parts of Asia and Africa. As the project evolved, not all interactions, even within Gujarat, were positive. We will discuss this in the social change section below. However, the involvement of several different international and domestic actors created a synergy that continued to focus on the work of the international and domestic NGOs.

\subsection{The Presence of TANs Is Indicated through the Formation of Dense Webs of Connections that Continually Are Redefined}

As Keck's and Sikkink's theoretical research predicted, it is indeed almost impossible to track Bhungroo's webs of connections, first, because of the complex synergy that has been created within the project and, second, because of how it has been integrated into the larger networks of climate change and gender equity. The fact that Bhungroo continues to gain recognition and secure awards is significant. The nature of the problem —as a global environmental challenge-means that the webs of connections are continually and incrementally redefined as people continue to become aware of the effects of climate change. For instance, Oxfam identified the Bhungroo technology as critical to helping farmers continually adapt to the negative impacts of climate change. In the Oxfam report, Biplab acknowledges that India faces drastic unpredictable weather conditions and resulting droughts and food insecurity,

"Bhungroo is a small step in the right direction. It's a solution that's easy on the pocket for farmers, and easier to maintain as well."

\subsection{TANs Facilitate the Launching of Mass Media Campaigns Specifically to Influence Public Opinion}

One indicator of the presence of TANs is the UNFCCC's Momentum for Change media strategy. The UNFCCC's strategy used several tactics to promote Bhungroo and the other winners. For example, the strategy included making connections with policy makers, increasing online and other media outreach, and professional training. In turn, these activities led to several media publications in various news outlets in what are referred to as "media hits".

Because of the explosion of social and other media outlets, as theorists predicted, it is difficult to track all the media hits related to Bhungroo. According to the lead communications officer in the Momentum for Change initiative, earned media hits are only one part of an ongoing communications campaign and public relations support to drive attention to winning activities. This includes promoting Bhungroo through social media, as well as producing a promotional video (https:/ /vimeo. com/125792111) and publishing the UNFCCC's annual report online (Sarah Marchildron, email communication, 25 April 2018).

Taken together, the five dimensions of TANs (Sections 4.1-4.5 above) resonate with and can help locate the Bhungroo project within a larger global network of climate change adaptation and gender equity initiatives. The way in which Naireeta Services fits within a larger global structure theoretically helps us understand what TANs are and how they facilitate both local and global goals. Additionally, it appears that TANs helped increase the visibility and funding of Naireeta Services so that it could expand its geographical range and scope. Through TANs, Bhungroo technology has been promoted as essential to reducing urban migration, improving food security, and increasing women's political participation in several areas [45-47]. 


\section{Appiah's Social Change Measures in Bhungroo Irrigation Technology}

The ability of the Bhungroo project to promote social change is essential as is bridging the project's connections within TANs and increasing its geographical range and scope. Therefore, in order to assess the Bhungroo project's ability to create social change at the local level, we apply a common model of social change established by philosopher and cultural theorist Kwame Anthony Appiah [22]. Appiah used as his case study foot binding in China in the late 1800s to identify specific measures of social change, asserting that understanding the elements that made for success against foot binding would enable others to find examples of what to do and what not to do [23]. Our intention here is to test Appiah's assertion by using Bhungroo as the case study. It is important to note that there is no comparison between climate change and rights for women and foot binding, and that we are not in any way making that comparison. Instead, we are only using Appiah's model of social change as applicable to our case.

To detect the presence or absence of Appiah's social change measures, we compare six media reports published between to 2015 to 2017 to our in-depth interviews with Trupti and Biplab. We believe that it is possible to analyze the language that is used in the public sphere to predict the likelihood that fundamental social change is occurring in terms of women's political empowerment. According to Appiah, the development and support of on-the-ground organizations is crucial. He posits that fundamental social change occurs when:

(1) The community signs a pledge to change;

(2) It establishes an organization (e.g., a local NGO) so as to combat isolation;

(3) The organization elicits promises from the younger generation to support the change;

(4) The organization builds networks inside and outside the country;

(5) The organization speaks the language that people revere;

(6) The community (and the associated organizations) define a "new normal;"

(7) The program is not linked to a larger, amorphous concept;

(8) The government is not the primary instigator (i.e., does not make laws to force change);

(9) "The change" is based on respect, not self-congratulation;

(10) The community and public-at-large is committed to the change; and

(11) Old practices are replaced by something new.

A few of Appiah's measures above occurred in Gujarat after the technology was introduced. In the first measure above, although the community did not sign a formal pledge, it was involved at the very beginning of the project. In the second measure, after some time, Trupti and Biplab formed the domestic NGO, Naireeta Services, to house the Bhungroo technology. As to the third measure, it is not clear whether the organization promised the younger generation anything to garner their support. We will need to examine this over a longer time period. On the other hand, the fourth measure was thoroughly operative, since the Bhungroo technology built networks inside and outside of the country. These connections contributed to the success of the Bhungroo irrigation technology to be implemented in other nations. There is also media outreach that continues to build networks outside of the country. In the fifth measure, both Trupti and Biplab spoke the mother tongue in Gujarat and appealed to the sensibilities of the local population. They effectively explained in Gujarati the crucial roles of women farmers, which included pointing out that most of the women stayed in Gujarat and thus were qualified to lead; whereas the men often were absent from the community since they migrated to other parts of India to find work.

It appears that the sixth measure of social change most closely resembles the efforts of Naireeta Services to promote social change. For example, the success of the organization and technology allowed for the community to define a 'new normal' in terms of gender relations. Our interviews with Trupti and Biplab also indicated that local women became empowered to become involved politically in their community. Women owned the very technology that made the land usable. This helped 
them increase their social position and gave them access to local government participation in the "panchayat." Trupti said:

"Our many women have been in contested elections at the local Penjyad (the village governing body) in the village of Mehtan. In India, in 1992, the 70th Amendment was passed in the constitution of India. So now the 70th Amendment is saying that at least 33\% of the seats for the Penjyad (the village governing body) are reserved for women only. What was happening was that the dummy candidates had been put on the Penjyad because men don't know that the seats were reserved for women; and, even if they did know they don't know how to work it out and make the decisions. So, in the name of the women, only men were always working in the Penjyad."

Though the state government deemed that women were to be represented in local government, at first, men took the place of women even though the law aimed to include the women. However, according to Trupti, the Bhungroo technology enabled the women to become empowered politically. Trupti said:

"Women want to take part in the micro planning process by contesting the election in the Penjyad. Women consistently take elections to stand in the Penjyad elections and the contested elections are in front of all the male members. The women members are based on the party. They take the positions that they want to work for the Penjyad-they stood for it."

The technology empowered women to take on political positions to improve their households and village. Women's representation in local government in this area may eventually help with other issues around gender relations; however, it was the strategy of introducing the irrigation technology-not the law-that allowed for this social change to occur. This also exemplifies the eighth measure of social change.

Seventh, though the program obviously is linked to the larger concepts of climate change adaptation and gender equity, the program goes about achieving change within the context of its origination. For instance, the technology helped circumvent women's lack of land rights to overcome gender inequity by giving them the technology that made the land useful rather than continuing to fight for formal land rights.

Eighth, as exemplified earlier, the government was not the instigator in this project, although it now supports areas of the project and organization. Therefore, one advantage of Bhungroo is that it recognizes that social change will not come from passing laws. Ninth, though the project has earned many sought-after awards, Trupti and Biplab and their numerous supporters do not congratulate themselves on their accomplishments. Instead, they continue to work with local farmers to find ways to apply the irrigation technology in different geographical regions so as to grow and expand Bhungroo. Tenth, while not everyone in the community or the world is supportive of combining climate change adaptation with empowering women, Bhungroo specifically identifies the poorest women who can benefit from the technology. In some ways, we wonder if this may be counterproductive. That is, by focusing only on the poor, social change (in terms of enabling a wide range of women to take on leadership roles) may not be fully realized.

Eleventh and lastly, old practices of women not engaging in local government were replaced with women taking the initiative in managing Bhungroo, so they can work on what is needed. For instance, Trupti informed us that by getting women involved in the Bhungroo projects, they began to negotiate with the local government to fund more relevant programs relating to the issues they experience. Therefore, less money is wasted on unfeasible or unsuccessful projects from the state and more focus is placed on programs that are appropriate for the needs of the community.

To test the theoretical constructs of transnational advocacy networks and social change, we decided to analyze the way the UNFCCC's Momentum for Change campaign "pitches" the importance of the Bhungroo project in the public media. 


\section{The Effectiveness of the UNFCCC Momentum for Change's Political Campaign Strategy}

Bhungroo's receipt in 2014 of the Momentum for Change "Women for Results" Award from the UNFCCC led to the implementation of a mass media campaign of "earned media" (i.e., articles in key new sources around the world) in the Times of India, The Daily Star, and Forbes between 2015 and 2017. This campaign is one component of a larger but significant part of the UNFCCC's information politics strategy to promote the work of the Momentum for Change awardees. Our analysis of the language used in six of the publications helps us to determine whether three crucial elements, derived from Appiah's social change measures above, appear to be operative: specificity (i.e., Do the articles describe the project or couch it in larger, amorphous concepts?), appeal (Is the language intended to gain international support and/or does it represent the cultural values and norms of women's roles in Asia?), and advocacy (Do the articles attempt to elicit public commitment and/or do the articles acknowledge the significant obstacles to social change?).

\subsection{Specificity}

One 2015 news report written by S. Aijaz [46] in Social Story illustrates the first measure of social change, detailing the extent to which the local community in Gujarat became involved in Bhungroo and how it was being used in other parts of India, as below:

"Bhungroo is executed through community cultivation not just to protect farmers from being exploited but to make a secure future for women. At least five poor women smallholders enter into a pre-agreement that they'll jointly manage their Bhungroo, share irrigation water and contribute to labour in each other's lands. The Bhungroo year-one installation cost starts at INR 9 lakhs. One Bhungroo unit can last for 20 years. With this cooperation, it can cater to 21 acres of land during both monsoon and winter."

The news reports consistently provided visual and technical details on how the irrigation technology works as well as how it can be used in different geographical regions, for example, in The Better India posted by Tanaya Singh [45]:

"The high salinity of soil in arid regions of Gujarat and other states creates an impermeable layer that prevents rainwater from seeping in. This leads to water logging and the standing water again increases the salinity of the soil. Bhungroo helps farmers in such rain-scarce and salinity-prone areas. The system consists of a pipe erected in such a way that excess water passes through it, gets filtered and accumulates in an underground well. Later, farmers use a motor to pump the water up and use it for irrigation... The underground reservoir can hold 40 million litres of water and can supply for as long as seven months. Additionally, the non-saline rain water, when mixed with the underground saline water, brings down the salinity of the groundwater and makes it fit for agriculture."

In addition, the reports use Mahatma Gandhi's principles to speak the language that people revere-the fifth measure above in Appiah's social change theory, for example by S. Aijaz in Social Story [44], who quotes Trupti:

"That is the precise objective of Naireeta Services," says Trupti. "We are trying to follow Mahatma Gandhi's principle of Antodaya, i.e., serving the last person in the queue in the best possible way."

One area of concern, however, is when the language becomes too intertwined with the program, as represented in the seventh social change measure above. One example of this, from the Forbes \#NewTech news report by Suparna Dutt D'Cunha [48], who quotes Biplab using the concepts of "sustainable development" and "food security, which primarily are understood outside of the local community":

“We are now going to focus on 12 drought-prone states of India, and by 2022, we aim to cater to 1 million farmers, which will help in inching closer to the UN initiative of sustainable development goal of food security for all." 
If the concepts are intended for an international and not a local audience, then it seems that the potential for social change in Gujarat would not be adversely affected. However, over time, there may be tension between the presumably "local" language of Gandhi and the global language of environmental sustainability if, as discussed below, the cultural values and norms of Gujarati women are not acknowledged.

\subsection{Appeal}

From the online publication, Your Story, S. Aijaz [46] describes the way Trupti and Biplab dealt with resistance in the Gujarati community:

"Trupti had to face a lot of opposition from the men folk who were particularly against Bhungroo being centered around women. Trupti says, "NSPL was non-negotiable on this subject; male members were migratory .... . To them, Naireeta Services [NSPL] was trying to jeopardise their monopoly and land-capturing schemes ... Naireeta's problems were seemingly endless. "Nearly moneyless smallholders were not able to mobilise a single penny for the work," says Trupti. Women had to be convinced to take part and involve their families to install Bhungroo."

This kind of resistance may not be mediated by appeals from international organizations because the Bhungroo program aims to alter and replace well-established socio-cultural norms. The community is comprised of semi-literate farmers and laborers who need to see the benefits of the new practices, as represented in the eleventh social change measure in the previous section. Essentially, the news report in the Times of India, which lauded the program for getting global recognition at the UN Climate Change Conference (UNCCC) in Lima, Peru is of little practical value at the community level.

On the other hand, the Forbes \#New Tech article filed by Suparna Dutt D'Cunha [48] reports that appealing to both regional and international communities facilitate the expansion and refinement of the Bhungroo program. For example, Bhungroo has gained recognition from the South Asian Association for Regional Cooperation (SAARC), which is particularly important because the SAARC focuses on helping rural communities that are struggling to survive, as described below:

"So when a few showers fell in mid-July in Latur, one of the hardest-hit areas, the 47-year-old ran outside to plant pulses and sweet potatoes, scattering seeds, and pushing vines into the moistened earth. For the last six months, Patil and his family of eight have relied on one meal a day, while many desperate farmers have killed themselves-more than 400 farmers committed suicide this year, and more than 2000 in 2015."

A news report by Sushmita S. Preetha [49] in The Daily Star in Bangladesh used language that integrated local and global issues. On the one hand, it mentioned that the Bhungroo program focused on improving the lives of the poorest women who would then be enabled to become involved in the political process [50]:

"The beneficiaries are identified following a thorough three-tiered selection process: first, the women of a given village identifies the poorest woman in their community; second, the list is crosschecked by women from surrounding villages; and finally, the list is vetted again at the sub-district level to ensure that the intervention reaches the targeted community ... "Our beneficiaries had an annual income less than USD 120. Today, they are earning USD 800-1000 every three months. Everybody has settled their loans. They are living secure lives, and are even taking part in the political process," says [Biplab] Paul."

On the other hand, the Daily Star [49] reports on how and why Bhungroo received international recognition:

"What is more, as the United Nations Framework on Climate Change Convention (UNFCCC) notes, "by curtailing desertification, the technology helps to build resilience to climate change 
and to rejuvenate local biodiversity." As such, it doesn't simply benefit the direct beneficiaries, but also the local communities by facilitating more crop, biodiversity and nutritious food, an outstanding feat which won Bhungroo the UNFCCC's Momentum for Change award."

Taking all of the social change measures into account, it seems likely that the international recognition and on-the-ground attention are complementary in Gujarat. However, as will be discussed in the conclusion, it is not clear whether women's political participation/empowerment will be transferable to local communities throughout Asia and Africa without substantial modifications [51].

\subsection{Advocacy}

Finally, a vital component of social change is whether a particular program elicits public commitment and, at the same time, acknowledges the obstacles. Social Story does provide a clear description of the benefits and challenges of the Bhungroo program and this is also the case in The Daily Star. In another media hit from an inspirational online news source, The Better India, Tanaya Singh [43] described how Biplab became involved in the Bhungroo program:

"During relief work after the earthquake, he organised women from the villages to develop a remediation plan for their water issues. This was when he realised that mobilized women can lead to high-impact social change. He developed the Bhungroo technology in the year 2000 , and it took 14 years to streamline the process after many trial and error sessions."

In this advocacy framework, the report cites Biplab in describing the power of combining international and community organizations, which mirrors our study of TANs:

“Now, with knowledge guidance from Ashoka India, a network of social entrepreneurs worldwide, the organization has adopted a partnership model. Different NGOs, cooperatives, institutions, CSR wings of organizations, etc., partner with Naireeta Services to become carriers of the technology. The entire process of setting up Bhungroo is led by women. Naireeta Services, or partner organizations, train members of women Self Help Groups (SHGs) in different villages."

\section{The Benefits and Limitations of Bhungroo in Facilitating Long-Lasting Social Change}

As on-the-ground projects similar to the Bhungroo case study come into existence and continue to expand to adapt to climate change and empower women, it is important to understand their location within TANs. We argue that TANs may help increase the scale and scope of these projects, increasing their ability to reach more people and geographical regions. This process is made possible through several avenues we reviewed in this article, such as building partnerships and receiving funding and awards internationally such as through the UNFCC. While increased funding and technical support are critical to scaling up and expanding projects, media outreach also is essential to the expansion of TANs, so that activities can grow. In our case study, three questions remain.

First, we need to learn more about how the Bhungroo technology has transferred to different countries and regions. Trupti and Biplab have discovered multiple uses of the technology-in areas that are either too wet or too dry-but it is not yet clear whether Bhungroo will be a primary answer, even in a small way, to climate change adaptation globally.

Second, we wonder whether the Bhungroo program will be managed in such a way that a "new normal" in terms of women's political participation and social status will be established. Perhaps there are different practices in terms of sustainable women's roles and even a different cultural dynamic between farmers and laborers in different countries in Asia and Africa. TANs would need to be fully operative and include "champions" within communities. Furthermore, local NGOs will need to ensure that the program utilizes local women's strengths and perspectives. One legacy from the Bhungroo project is that Trupti and Biplab are thoroughly committed to keeping both climate change and gender equity at the forefront. 
Finally, because the program still is relatively new, it is not yet apparent whether future generations of Gujarati women will assume leadership roles. While building progress in terms of a continuous integration of women in the Penjyad (the village governing body) may increase women's political participation within the area and in larger government roles, it is not possible to know its long-term effect. It is clear, however, that Bhungroo is a useful, functioning case study of how a local NGO can fit into and flourish within a TAN.

Author Contributions: Both authors are responsible for Conceptualization; Methodology, Writing-Review \& Editing. Funding: This research received no external funding.

Acknowledgments: We want to acknowledge Trupti Jain, Sarah Marchildron, and those at the UNFCCC for providing us with the information necessary to write this article.

Conflicts of Interest: The authors declare no conflict of interest.

\section{References}

1. Intergovernmental Panel on Climate Change. Climate Change 2014: Mitigation of Climate Change; Cambridge University Press: Cambridge, UK, 2015; Volume 3.

2. Van Oldenborgh, G.J.; Philip, S.; Kew, S.; van Weele, M.; Uhe, P.; Otto, F.; Singh, R.; Pai, I.; Cullen, H.; AchutaRao, K. Extreme heat in India and anthropogenic climate change. Nat. Hazards Earth Syst. Sci. 2018, 18, 365. [CrossRef]

3. Carley, M.; Christie, I. Managing Sustainable Development; Routledge: Abingdon, UK, 2017.

4. Sharma, D.; Tomar, S. Mainstreaming climate change daptation in Indian cities. Environ. Urban. 2010, 22, 451-465. [CrossRef]

5. UNFCCC. Momentum for Change. 2016. Available online: http://momentumforchange.fluidreview.com/ res/p/essential-information (accessed on 2 April 2018).

6. Keck, M.E.; Sikkink, K. Transnational advocacy networks in international and regional politics. Int. Soc. Sci. J. 1999, 51, 89-101. [CrossRef]

7. Christoff, P.S.; Lewis, N.D.; Lu, M.; Sommer, J.S. Women and Political participation in India, Indonesia, Thailand, and Vietnam: A Preliminary Analysis of the Local Impact of Transnational Advocacy networks in Climate Change. Asian Women 2017, 22, 1-22. [CrossRef]

8. Anttila-Hughes, J.; Hsiang, S. Destruction, Disinvestment, and Death: Economic and Human Losses Following Environmental Disaster. 2013. Available online: http://dx.doi.org/10.2139/ssrn.2220501 (accessed on 2 April 2018).

9. Aguilar, L.; Granat, M.; Owren, C. Roots for the future: The landscape and way forward on gender and climate change. In Global Gender and Climate Alliance and International Union for Conservation of Nature; IUCN \& GGCA: Washington, DC, USA, 2015.

10. Lai, M.Y. Dancing to different tunes: Performance and activism among migrant domestic workers in Hong Kong. Women's Stud. Int. Forum 2010, 33, 501-511. [CrossRef]

11. Zeng, B. Women's political participation in China: Improved or not? J. Int. Women's Stud. 2014, 15, 136.

12. Bennett, N.; Dearden, P.; Murray, G.; Kadfak, A. The capacity to adapt? Communities in a changing climate, environment, and economy on the northern Andaman coast of Thailand. Ecol. Soc. 2014, 19, 2. [CrossRef]

13. Agarwal, B. Gender, Property, and Land Rights: Bridging a critical gap in economic analysis and policy 1. In Gender and Rights; Routledge: Abingdon, UK, 2017; pp. 119-149.

14. Arwida, S.D.; Maharani, C.; Sijapati Basnett, B.; Yang, A.L. Gender Relevant Considerations for Developing REDD+ Indicators: Lessons Learned for Indonesia; CIFOR: Bogor, Indonesia, 2017; Volume 168.

15. Agarwal, B. Gender and Green Governance: The Political Economy of Women's Presence: Within and Beyond Community Forestry; Oxford University Press (OUP): Oxford, UK, 2015.

16. Leisher, C.; Temsah, G.; Booker, F.; Day, M.; Samberg, L.; Prosnitz, D.; Agarwal, B.; Matthews, E.; Roe, D.; Russell, D.; et al. Does the gender composition of forest and fishery management groups affect resource governance and conservation outcomes? A systematic map. Environ. Evid. 2016, 5, 6. [CrossRef]

17. Hadden, J.; Jasny, L. The power of peers: How transnational advocacy networks shape NGO strategies on climate change. Br. J. Political Sci. 2017, 1-23. [CrossRef] 
18. Norman, D.J. Building democratic public spheres? Transnational advocacy networks and the social forum process. Glob. Netw. 2017, 17, 300-317. [CrossRef]

19. Aday, S.; Livingston, S. Taking the state out of state-Media relations theory: How transnational advocacy networks are changing the press-State dynamic. Media War Confl. 2008, 1, 99-107. [CrossRef]

20. Carpenter, R.C. Setting the advocacy agenda: Theorizing issue emergence and nonemergence in transnational advocacy networks. Int. Stud. Q. 2007, 51, 99-120. [CrossRef]

21. Keck, M.E.; Sikkink, K. Activists beyond Borders: Advocacy Networks in International Politics; Cornell University Press: Ithaca, NY, USA, 2014.

22. Appiah, K.A. The Honor Code: How Moral Revolutions Happen; W.W. Norton and Company: New York, NY, USA, 2010.

23. Appiah, K.A. The Art of Social Change. Available online: https://www.nytimes.com/2010/10/24/ magazine/24FOB-Footbinding-t.html (accessed on 2 April 2018).

24. Women's Earth \& Climate Action Network International. Why Women Are Key; WECAN International: Mill Valley, CA, USA, 2016. Available online: http://wecaninternational.org/why-women-are-key $\backslash \mathrm{T} 1 \backslash$ textgreater\{\} (accessed on 2 April 2018).

25. WEN. Women's Environmental Network. 2017. Available online: https://www.wen.org.uk (accessed on 2 April 2018).

26. Norgaard, K.; York, R. Gender equality and state environmentalism. Gend. Soc. 2005, 19, 506-522. [CrossRef]

27. Pang, X.; Zeng, J.; Rozelle, S. Learning but not acting in rural China. Asian Surv. 2014, 54, $1009-1036$. [CrossRef]

28. Ergas, C.; York, R. Women's status and carbon dioxide emissions: A quantitative cross-national analysis. Soc. Sci. Res. 2012, 41, 965-976. [CrossRef] [PubMed]

29. Lake, O.O. Why Women Are Central to Climate Justice and Solutions. 2015. Available online: http: / / ecowatch.com/2015/09/24/women-climate-change/ (accessed on 2 April 2018).

30. DeVoe, W.D.; DiLanzo, T.; Dunn, L.; Iversen, K.; Malter, J.; Papp, S.; Russo, S. Invest in Women to Tackle Climate Change and Conserve the Environment. 2016. Available online: http://womendeliver.org/ wpcontent/uploads/2016/09/Good_Campaign_Brief_10_092016.pdf (accessed on 2 April 2018).

31. Alam, M.; Bhatia, R.; Mawby, B. Women and Climate Change: Impact and Agency in Human Rights, Security, and Economic Development; Georgetown Institute for Women, Peace and Security: Washington, DC, USA, 2015.

32. True, J.; Niner, S.; Parashar, S.; George, N. Women's political participation in Asia and the Pacific. In Social Science Research Council: Conflict Prevention and Peace Forum; Social Science Research Council: West Brooklyn, NY, USA, 2012.

33. Jordan, J.C. Deconstructing resilience: Why gender and power matter in responding to climate stress in Bangladesh. Clim. Dev. 2018, 1-13. [CrossRef]

34. Benschop, Y.; Verloo, M. Sisyphus' sisters: Can gender mainstreaming escape the genderedness of organizations? J. Gend. Stud. 2006, 15, 19-33. [CrossRef]

35. Eveline, J.; Bacchi, C. What are we mainstreaming when we mainstream gender? Int. Fem. J. Politics 2005, 7, 496-512. [CrossRef]

36. Schipper, E.L.F.; Le Masson, V.; Langston, L.; Kratzer, S.; Sogani, R.; Nyukuri, E.; Arana, M.T. Closing the Knowledge Gaps on Gender and Climate Change for CCD. In Making Climate Compatible Development Happen; Routledge: Abingdon, UK, 2017; p. 44.

37. Reed, M.G. Understanding the gendered labours of adaptation to climate change in forest-based communities through different models of analysis. In Climate Change and Gender in Rich Countries: Work, Public Policy and Action; Routledge: Abingdon, UK, 2017; p. 199.

38. Mapfumo, P.; Onyango, M.; Honkponou, S.K.; El Mzouri, E.H.; Githeko, A.; Rabeharisoa, L.; Obando, J.; Omolo, N.; Majule, A.; Denton, F.; et al. Pathways to transformational change in the face of climate impacts: An analytical framework. Clim. Dev. 2017, 9, 439-451. [CrossRef]

39. Singh, J.P. Transnational, National, or Local? Gender-based NGOs and Information Networks in India. In Crises of Governance in Asia and Africa; Routledge: Abingdon, UK, 2017; pp. 127-146.

40. Wen, N.; Xiaoming, H.; George, C. Gender and political participation: News consumption, political efficacy and interpersonal communication. Asian J. Women's Stud. 2013, 19, 124-149. [CrossRef] 
41. Buranajaroenkij, D.; Doneys, P.; Kusakabe, K.; Doane, D.L. Expansion of Women's Political Participation through Social Movements: The Case of the Red and Yellow Shirts in Thailand. J. Asian Afr. Stud. 2018, 53, 34-48. [CrossRef]

42. Ihalainen, M.; Sijapati Basnett, B. Gender and Climate Change: Evidence and Experience; No. Gender Climate Brief No. Intro.; Center for International Forestry Research (CIFOR): Bogor, Indonesia, 2015.

43. Naireeta Services. Bhungroo. 2018. Available online: http://www.naireetaservices.com (accessed on 2 April 2018).

44. Christoff, P.; Sommer, J. Personal Interview with Trupti Jain and Biplab Paul; Stony Brook University: Stony Brook, NY, USA, 2016.

45. Singh, T. This Man Is Helping Farmers Fight Both Dry Spells and Water Logging with a Unique RWH Technology; The Better India: Bengaluru, India, 2016. Available online: https:/ / www.thebetterindia.com/62677/watermanagement-gujarat-bhungroo/ (accessed on 2 April 2018).

46. Aijaz, S. Antodaya to the Tune of Bhungroo: Saving Rural India's Lost Families; Your Story: Bangalore, India, 2015. Available online: https:/ / yourstory.com/2015/06/antodaya-tune-bhungroo-saving-rural-indias-lostfamilies / (accessed on 2 April 2018).

47. Landek, S. TOR174-The Bhungroo Innovation for Agriculture with Trupi Jain of Naireeta Services. Aidpreneur. 2017. Available online: http://aidpreneur.com/tor174-the-bhungroo-innovation-foragriculture-with-trupi-jain-of-naireeta-services/ (accessed on 2 April 2018).

48. Dutt D'Cunha, S. This Simple Indian Irrigation Tech Is Helping Farmers Hit Hardest By Climate Change \& Drought; Asia New Tech.; Forbes: New York, NY, USA, 2016. Available online: https:/ / www.forbes.com/sites/suparnadutt/2016/09/07/this-simple-indian-irrigation-tech-is-helpingfarmers-hit-hardest-by-climate-change-drought/\#35390ea7db69 (accessed on 2 April 2018).

49. Preetha, S. Bhungroo: Watering Dreams and Livelihoods. The Daily Star, 25 June 2016, p. 1.

50. Inspiring Social Entrepreneurs. Episode 77: Interview with Biplab Ketan Paul, Founder of Naireeta Services. 2017. Available online: http:/ /inspiringsocialentrepreneurs.com/episode-77-interview-with-biplab-ketanpaul-founder-of-naireeta-services / (accessed on 2 April 2018).

51. Garg, A.; Stock, R.; Brikenholtz, T. Let the people speak: Improving regional adaptation policy by combining adaptive capacity assessments with Vulnerability perceptions of farmers in Gujarat, India. Clim. Dev. 2017, 1-15. [CrossRef]

(C) 2018 by the authors. Licensee MDPI, Basel, Switzerland. This article is an open access article distributed under the terms and conditions of the Creative Commons Attribution (CC BY) license (http:/ / creativecommons.org/licenses/by/4.0/). 